\title{
0 acesso à educação superior na Universidade Federal da Grande Dourados: trajetória de estudantes ingressantes entre
} 2006-2009

\author{
Access to higher education in the Federal University of Grande Dourados: \\ trajectory of incoming students between 2006-2009 \\ El acceso a la educación superior en la Universidad Federal de la Grande \\ Dourados: trayectoria de los alumnos ingresantes entre 2006-2009 \\ JOSÉ DA SILVA SANTOS JUNIOR \\ GISELLE CRISTINA MARTINS REAL
}

Resumo: O objetivo do artigo é analisar os índices de evasão, de permanência prolongada e de conclusão de curso de graduação na Universidade Federal da Grande Dourados, procurando-se relacionar os dados quantitativos aos fenômenos da trajetória acadêmica em períodos de expansão da Educação Superior. A metodologia utilizada é de acompanhamento de coorte, interpretandose os dados por meio de estatística descritiva. Os resultados mostraram aumento real, entre 2006 e 2009, na retenção de estudantes ingressantes na instituição, bem como uma diminuição dos percentuais de concluintes ao longo dos anos.

Palavras-chave: Políticas de Educação Superior; evasão; permanência prolongada; conclusão de curso.

\begin{abstract}
The aim of the article is to analyze the rates of dropout, prolonged stay and graduation in the Federal University of Grande Dourados. We seek to relate the quantitative data to the phenomena of the academic trajectory in periods of expansion of higher education. The methodology used is cohort followup, interpreting the data using descriptive statistics. The results showed a real increase in the prolonged stay of incoming students between 2006 and 2009 in the institution, as well as a decrease in the percentage of graduates over the years.

Keywords: higher education policies; dropout; prolonged stay; graduation.

Resumen: El objetivo de este artículo es analizar las tasas de abandono, la permanencia prolongada y de conclusión de curso de graduación en la Universidad Federal de la Grande Dourados, buscando relacionar las datos cantitativos a los fenómenos de la trayectoria académica en los períodos de expansión de la educación superior. La metodología utilizada es la supervisión de cohortes, interpretando los datos mediante estadística descriptiva. Los resultados mostraron un aumento real de la retención de los estudiantes de primer año entre 2006 y 2009 en la institución, así como una disminución en el porcentaje de concluyentes a lo largo de los años.
\end{abstract}

Palabras clave: Políticas de educación superior; evasión; permanencia prolongada; finalización de curso. 


\section{INTRODUÇÃO}

O objetivo do presente artigo é analisar os índices de evasão, de permanência prolongada e de conclusão de curso de graduação na Universidade Federal da Grande Dourados (UFGD), procurando-se relacionar os dados quantitativos à complexidade dos fenômenos da trajetória acadêmica em períodos de expansão da Educação Superior.

Verifica-se que, nas últimas décadas, especialmente a partir de meados de 1990, um conjunto de ações favoreceu o crescimento significativo da Educação Superior no Brasil. As políticas governamentais estabelecidas contribuíram para um crescimento exponencial de matrículas nesse nível de ensino, elevando o número ${ }^{1}$ de matrículas em aproximadamente 293,1\% entre os anos de 1991 e 2013. A literatura registra esse processo como um período de transição entre um "sistema de elite" para um "sistema de massa" (GOMES; MORAES, 2012, p.180), indicando que houve expansão relevante das possibilidades de ingresso aos estudantes, sobretudo a partir da década de 2000.

Constata-se que a implementação de programas e ações específicas foi incisiva para a tentativa de consolidação da Educação Superior no país. Dentre tais ações, destacaram-se: o Programa Universidade: expandir até ficar do tamanho do Brasil, de 2004; o Programa de Apoio a Planos de Reestruturação e Expansão das Universidades Federais (Reuni), de 2007; o Programa Nacional de Assistência Estudantil (Pnaes), de 2010; o Programa Nacional de Assistência Estudantil para as Instituições de Educação Superior Públicas Estaduais (Pnaest), de 2010; o Programa Universidade para Todos (Prouni), de 2005; o Fundo de Financiamento Estudantil (Fies), de 1999; os Institutos Federais de Educação, Ciência e Tecnologia (Ifets), de 2008; e o Sistema Universidade Aberta do Brasil (UAB), de 2006. Além desses, outras políticas influenciaram a expansão do acesso, como é o caso da implementação da Lei de Cotas, Lei no. 12.711/2012.

Neste contexto de expansão, foi criada a UFGD, a partir de desmembramento da Universidade Federal de Mato Grosso do Sul (UFMS), por meio da Lei $n^{\circ} 11.153$, de 29/07/2005. Esse ato de criação favoreceu o atendimento de um número significativo de estudantes de vários municípios do interior do estado de Mato Grosso do Sul, configurando-se como ação relevante da reforma universitária proposta pelo governo federal, que, embora considerada como não-integralizada (CARVALHO, 2015), possibilitou a expansão das universidades federais para regiões interioranas, como é o caso da instituição em discussão. 1 Número calculado a partir dos dados das Sinopses Estatísticas do Censo da Educação Superior,
disponíveis no site www.inep.gov.br. Acesso em 22 ago. 2014. (BRASIL, 2015).

468 - RBPAE - v. 33, n. 2, p. 467 - 492, mai./ago. 2017 
Com a sanção de sua Lei de criação, a UFGD, que já havia herdado 12 cursos de graduação da UFMS, criou no ano seguinte mais sete cursos, o que possibilitou a expansão de vagas nos processos seletivos da instituição. Ao todo, foram oferecidas 850 vagas no vestibular de 2006, 860 em 2007, 967 em 2008 e, com o advento do Reuni, mais nove cursos foram criados, sendo ofertadas 1148 vagas em 2009.

Torna-se oportuno considerar que o movimento de expansão nacional implicou repensar a questão da permanência e da formação dos estudantes. Nessa direção, a Secretaria de Educação Superior do Ministério da Educação (Sesu/ MEC) divulgava, ainda na década de 1990, indicadores que apontavam para uma evasão média de 50\% nas universidades federais brasileiras (BRASIL, 1997). E, entre os anos de 2009 e 2011, em estudo preliminar do Grupo de Trabalho para Estudos sobre Evasão Acadêmica ${ }^{2}$, divulgou uma média oscilante de 13\% nas taxas de evasão em oito Instituições Federais de Educação Superior ${ }^{3}$ (Ifes) (NUNES, 2013).

A literatura, embora com registros insuficientes (SILVA, 2013), tem trazido essa temática para o debate. Em levantamento bibliográfico realizado entre Abril/2014 e Janeiro/2015, verificou-se a publicação de sete teses de doutorado, 34 dissertações de mestrado e 31 artigos sobre evasão na Educação Superior, considerando-se para essa busca alguns dos principais bancos de dados nacionais ${ }^{4}$. Constatou-se que estudos relacionados às causas e/ou estratégias de controle da evasão correspondem aos principais focos de pesquisa com essa temática.

O presente trabalho é um estudo de caso, em que se considerou a UFGD como campo de pesquisa, por ser uma instituição criada em meio à formulação e implementação de políticas de expansão da Educação Superior brasileira, podendo estar representando a realidade mais ampla do sistema de Educação Superior do País.

A opção de estudo de caso é por retratar o espaço local, sendo fundamentada em Azevedo (1997), pois para a autora o espaço micro deve ser visto como fator relevante para as análises de políticas educacionais, dado que o âmbito local corresponde àquele em que a política pensada em um contexto mais

2 Instituído pela Sesu/MEC por meio da Portaria n ${ }^{\circ}$ 125, de 18 de julho de 2012.

3 É preciso esclarecer que as metodologias de cálculo utilizadas por Brasil (1997) e Nunes (2013) foram diferenciadas. Outros estudos nacionais ainda apresentam os dados de evasão nas Ifes. Em 2005, por exemplo, com metodologia própria, a taxa de evasão calculada por Silva Filho et al. (2007) foi de 11\% para o conjunto de Ifes.

4 Buscaram-se os termos "evasão" e "evasão acadêmica", recorrendo-se aos bancos de dados: Scientific Eletronic Library Online (Scielo), Grupo de Trabalho 11 da Associação Nacional de Pós-Graduação e Pesquisa em Educação (GT11/Anped), Banco de Teses e Dissertações da Coordenação de Aperfeiçoamento de Pessoal de Nível Superior (Capes) e Biblioteca Digital Brasileira de Teses e Dissertações (BDTD) do Instituto Brasileiro de Ciência e Tecnologia (IBICT). 
amplo se materializa. Em suas palavras: "Não se pode esquecer que a escola e principalmente a sala de aula, são espaços em que concretizam as definições sobre a política e o planejamento que as sociedades estabelecem para si próprias, como projeto ou modelo educativo que se tenta pôr em ação" (p. 50).

Utilizou-se a metodologia de acompanhamento de coorte, identificada neste trabalho, também, como trajetória escolar, analisando-se individualmente a situação acadêmica dos estudantes. Assim, não foi utilizada qualquer expressão matemática usual para a obtenção das taxas de evasão, permanência prolongada e conclusão. A obtenção dessas taxas se deu a partir da contagem dos estudantes enquadrados nessas situações e a posterior conversão dos números obtidos em porcentagens, as quais serão explicitadas ao longo das seções e interpretadas com o uso de estatística descritiva.

Importa ressaltar que o parâmetro metodológico para obtenção de dados para este artigo é diferente do procedimento utilizado por outros pesquisadores citados (NUNES, 2013; SILVA FILHO et al., 2007). Portanto, ficam inviabilizadas eventuais comparações, uma vez que os números aqui registrados não se referem a taxas anuais de evasão, mas de percentuais que envolvem todo o período necessário para a integralização do curso por estudantes de turmas específicas.

Identificaram-se três grupos distintos de alunos, tendo como parâmetro os ingressantes por vestibular entre os anos de 2006 e 2009 e sua situação no primeiro semestre de 2015. Foram segregados os estudantes evadidos ${ }^{5}$, os concluintes e, por fim, aqueles que ainda se encontravam matriculados no mesmo curso de ingresso, sendo denominados permanentes prolongados ou retidos ${ }^{6}$.

A problemática de pesquisa que se pretende responder ao final do artigo fica explicitada com a seguinte questão: como se comportam os processos de evasão, de permanência prolongada e conclusão de curso de graduação na UFGD, diante de um período de forte expansão da Educação Superior brasileira?

O corpo teórico para a análise dos dados é composto por autores que estudam a temática das políticas educacionais (SILVA; VELOSO, 2013; AZEVEDO, 1997; GOMES; MORAES, 2012) e outros que lidaram com estudos voltados para a compreensão de fenômenos da trajetória escolar (OLIVEIRA et al., 2004; TINTO, 1975).

$\mathrm{O}$ artigo está dividido em duas seções. Na primeira delas explicita-se o panorama geral da evasão, da permanência prolongada e da conclusão de curso na

\footnotetext{
5 Consideraram-se como evadidos os estudantes desistentes, excluídos pela instituição, excluídos por solicitação própria, jubilados ou movidos para outro curso na mesma IES. Não foram incluídos nas análises os alunos transferidos ou permutados para outra IES, bem como os estudantes falecidos. Estes, são mencionados ao longo da exposição de dados como "outras situações".

6 Os dados utilizados na pesquisa foram fornecidos pela Pró-Reitoria de Ensino de Graduação da UFGD.
} 
UFGD. A segunda seção apresenta algumas particularidades desses fenômenos, analisados por categorias sendo essas: colégio de conhecimento da Capes (Ciências Exatas, Tecnológicas e Multidisciplinar; Humanidades; Ciências da Vida), modalidade (licenciatura bacharelado) e turno de funcionamento do curso, com o intuito de se compreenderem padrões de comportamento dos processos em estudo.

\section{CARACTERÍSTICAS GERAIS DO ACESSO À EDUCAÇÃO SUPERIOR NA UNIVERSIDADE FEDERAL DA GRANDE DOURADOS}

Considera-se que o movimento de expansão ocorrido no país apresentou influências no âmbito institucional em que, embora com elevações importantes no número de vagas ofertadas desde sua criação, a UFGD explicitou algumas contradições no que se refere ao percurso dos estudantes ingressantes na instituição.

Em termos numéricos, os processos de evasão, de permanência prolongada e de conclusão de curso apresentaram, neste estudo, comportamentos diferenciados mas, ao mesmo tempo, com uma estreita relação entre eles.

Conforme série histórica apresentada a seguir (Tabela 1), as questões da permanência estudantil, assim como da formação acadêmica, trazem à tona preocupações relevantes, uma vez que as taxas de evasão na instituição apresentaram-se expressivas entre as turmas ingressantes nos anos de 2006 a 2009. 
Tabela 1 - Panorama da conclusão, da permanência prolongada e da evasão na UFGD para as turmas ingressantes entre os anos de 2006 a 2009

\begin{tabular}{|c|c|c|c|c|c|c|c|c|c|}
\hline Ano & $\begin{array}{c}\text { N } \\
N^{0} \text { de } \\
\text { ingressantes }\end{array}$ & \multicolumn{2}{|c|}{ Conclusão } & \multicolumn{2}{c|}{$\begin{array}{c}\text { Permanência } \\
\text { Prolongada }\end{array}$} & \multicolumn{2}{c|}{ Evasão } & \multicolumn{2}{c|}{ Outras situações } \\
\hline \multicolumn{2}{|c|}{} & $\mathrm{N}^{0}$ & $\%$ & $\mathrm{~N}^{0}$ & $\%$ & $\mathrm{~N}^{0}$ & $\%$ & $\mathrm{~N}^{0}$ & $\%$ \\
\hline $\mathbf{2 0 0 6}$ & 807 & 452 & 56,0 & 10 & 1,2 & 330 & 40,9 & 15 & 1,9 \\
\hline $\mathbf{2 0 0 7}$ & 860 & 471 & 54,8 & 30 & 3,5 & 344 & 40,0 & 15 & 1,7 \\
\hline $\mathbf{2 0 0 8}$ & 989 & 462 & 46,7 & 82 & 8,3 & 430 & 43,5 & 15 & 1,5 \\
\hline $\mathbf{2 0 0 9}$ & 1157 & 495 & 42,8 & 173 & 15,0 & 467 & 40,4 & 22 & 1,9 \\
\hline Total & $\mathbf{3 8 1 3}$ & $\mathbf{1 8 8 0}$ & & $\mathbf{2 9 5}$ & & 1571 & & $\mathbf{6 7}$ & \\
\hline
\end{tabular}

${ }^{7}$ Fonte: Elaboração própria a partir dos dados coletados na pesquisa

Observa-se uma ampliação de 43,4\% no número de vagas ofertadas entre os anos de 2006 e 2009, sendo esse um dos resultados proporcionados pelo movimento de expansão do acesso à Educação Superior brasileira das últimas décadas.

Entretanto, mesmo com esse aumento relevante do número de estudantes que adentraram a UFGD, os percentuais de evasão apresentaram-se expressivos, especialmente se considerado que quase metade dos alunos que ingressou não concluiu o curso.

Para Lobo (2012), é preciso colocar em pauta essa situação, uma vez que toda vez que um aluno evade do curso de ingresso, mesmo que a vaga seja ocupada por outros processos, houve uma perda, a qual precisa ser analisada com o intuito de se entender o processo e se evitarem novos abandonos.

Outra constatação importante que se pode extrair da Tabela 1 referese ao percentual de conclusão nos cursos da UFGD, verificando-se que houve diminuição ao longo dos anos pesquisados. Em 2006, pouco mais da metade $(56 \%)$ dos alunos obtiveram a formação pretendida. Em 2009, este número caiu para $42,8 \%$.

No entanto, é importante observar que esta diminuição de concluintes foi acompanhada por elevação do número de alunos em permanência prolongada. De 1,2\% verificados em 2006, o número de alunos ainda com vínculo ativo com a instituição subiu para 15\% em 2009. Com isso, somando-se os percentuais de

7 Não foram incluídos nas análises os alunos que realizaram transferência ou permuta para o mesmo curso em outra IES e os falecidos, denominados ao longo do trabalho como "outras situações". 
conclusão, permanência prolongada e outras situações, observa-se que o resultado mantém-se pouco oscilante, o que explicita que a diminuição do número de concluintes se dá mais em função da permanência prolongada do que da evasão.

Nessa direção, verifica-se proximidade nas diferenças percentuais obtidas entre a queda do número de alunos concluintes entre 2006 e 2009 (13,2\%) e o aumento dos permanentes prolongados no mesmo período $(13,8 \%)$. Este resultado, associado à taxa pouco oscilante da evasão, permite inferir que o processo de retenção apresentou-se de modo ascendente ao longo dos anos.

Essa inferência se torna mais clara ao se analisarem os dados de forma diferenciada, conforme a tabela 2 , em que se procurou detalhar os percentuais de alunos que concluíram o curso no seu tempo mínimo de integralização - "tempo ideal" estabelecido pela instituição para sua formação - e as taxas de estudantes que o concluíram em maior tempo.

Tabela 2 - Panorama da permanência prolongada e conclusão nos cursos de graduação da UFGD para os estudantes ingressantes nos anos de 2006 a 2009

\begin{tabular}{|c|c|c|c|c|}
\hline & $\begin{array}{c}\text { Total de } \\
\text { concluintes }\end{array}$ & $\begin{array}{c}\text { Concluintes no } \\
\text { tempo ideal }\end{array}$ & $\begin{array}{c}\text { Concluintes em } \\
\text { maior tempo }\end{array}$ & $\begin{array}{c}\text { Alunos em } \\
\text { permanência } \\
\text { prolongada }\end{array}$ \\
\hline Anos & $\%$ & $\%$ & $\%$ & $\%$ \\
\hline $\mathbf{2 0 0 6}$ & 56,0 & 38,7 & 15,7 & 1,2 \\
\hline $\mathbf{2 0 0 7}$ & 54,8 & 34,5 & 19,4 & 3,5 \\
\hline $\mathbf{2 0 0 8}$ & 46,7 & 30,0 & 15,7 & 8,3 \\
\hline $\mathbf{2 0 0 9}$ & 42,8 & 27,4 & 14,5 & 15,0 \\
\hline
\end{tabular}

${ }^{8}$ Fonte: Elaboração própria a partir dos dados coletados na pesquisa

Levando-se em consideração que os percentuais de evasão para o conjunto de cursos variaram entre $40 \%$ e 43,5\% (Tabela 1), com pouca variação nos anos pesquisados, reforça-se a tese de que os números constantes na Tabela 2 apontam para um aumento real do processo de retenção no âmbito da UFGD, uma vez que a diminuição do total de alunos concluintes e dos concluintes no tempo ideal foi acompanhada pelo aumento do número de alunos em permanência prolongada.

Esse fato pode ser ratificado quando se analisa o somatório de alunos concluintes em maior tempo e de alunos com vínculo ativo no curso, o qual pode

8 Destaca-se que, além dos concluintes em tempo ideal e em maior tempo, também há os casos de alunos que concluíram o curso antes do tempo mínimo de integralização, podendo se tratar de alunos com aproveitamento de estudos. Os percentuais referentes a estes alunos não foram incluídos na tabela, visto que não são alvo da investigação proposta. 
estar representando de modo aproximado à evolução do processo de retenção na UFGD. Obtém-se a soma de 16,9\% em 2006, 22,9\% em 2007, 24\% em 2008 e $29,5 \%$ em 2009.

Ao mesmo tempo, não se pode perder de vista que pode estar ocorrendo, ainda, uma combinação entre os processos de retenção e de evasão, configurandose como mais um agravante na trajetória acadêmica, uma vez que é aceitável que parte dos alunos evadidos possa ter sido alvo do processo de retenção quando do vínculo com a IES.

A tabela 3 apresenta as médias obtidas para a evasão, a permanência prolongada e a conclusão por curso de graduação da UFGD no período de estudo.

Tabela 03: Médias de evasão, permanência prolongada e de conclusão nos cursos $^{9}$ de graduação da UFGD para os estudantes ingressantes nos anos de 2006 a 2009

\begin{tabular}{|c|c|c|c|}
\hline CURSOS & EVASÃO & $\begin{array}{c}\text { PERMANÊNCIA } \\
\text { PROLONGADA }\end{array}$ & CONCLUSÃO \\
\hline Medicina & 2,5 & 1,5 & 94,5 \\
\hline Agronomia & 19,4 & 11,4 & 68,2 \\
\hline Pedagogia & 23 & 1,5 & 74,5 \\
\hline Direito & 26,3 & 2,6 & 67,8 \\
\hline Psicologia & 26,7 & 1,7 & 70 \\
\hline Engenharia de Energia & 28,3 & 39,6 & 30,2 \\
\hline Engenharia de Produção & 30,3 & 21,3 & 44,5 \\
\hline Biotecnologia & 30,4 & 1,8 & 67,9 \\
\hline $\begin{array}{c}\text { Letras - Português/ } \\
\text { Literatura }\end{array}$ & 30,7 & 2,3 & 67 \\
\hline $\begin{array}{c}\text { Ciências Biológicas - } \\
\text { Bacharelado }\end{array}$ & 33 & 0 & 51,8 \\
\hline Ciências Biológicas & 36,1 & 8,2 & 39,1 \\
\hline Nutrição & 37,3 & 11,9 & 45,5 \\
\hline Relações Internacionais & 38,2 & 10,9 & 46,3 \\
\hline Artes Cênicas & 40,7 & 13 & 52,5 \\
\hline Gestão Ambiental & 41,9 & 5,6 & 53 \\
\hline $\begin{array}{c}\text { Ciências Biológicas - } \\
\text { Licenciatura }\end{array}$ & 42,8 & 2,1 & 38,1 \\
\hline Administração & 44,4 & 14,5 & \\
\hline
\end{tabular}

9 Cumpre informar que houve reformulação de alguns cursos entre os anos pesquisados. Assim, alguns deles sofreram alterações de modalidade e/ou habilitação e foram incluídos individualmente na tabela. 
Tabela 03: Médias de evasão, permanência prolongada e de conclusão nos cursos de graduação da UFGD para os estudantes ingressantes nos anos de 2006 a 2009

\begin{tabular}{|c|c|c|c|}
\hline CURSOS & EVASÃO & $\begin{array}{c}\text { PERMANÊNCIA } \\
\text { PROLONGADA }\end{array}$ & CONCLUSÃO \\
\hline Economia & 47,9 & 33,3 & 16,7 \\
\hline História & 44,7 & 3,5 & 51,4 \\
\hline Ciências Contábeis & 46,7 & 10,7 & 38,9 \\
\hline Educação Física & 46,9 & 12,2 & 38,8 \\
\hline Ciências Sociais & 47,2 & 1,2 & 48,6 \\
\hline Química & 47,6 & 3,8 & 43,8 \\
\hline Letras - Português/Inglês & 47,9 & 0 & 49,7 \\
\hline Engenharia de Alimentos & 48 & 6,9 & 45,2 \\
\hline Zootecnia & 51,3 & 4,6 & 42,4 \\
\hline Engenharia Agrícola & 52 & 30 & 16 \\
\hline Geografia - Licenciatura & 53,5 & 2,4 & 25 \\
\hline Geografia & 52,8 & 22,5 & 38,4 \\
\hline Letras & 57,5 & 4,1 & 34,6 \\
\hline Geografia - Bacharelado & 59,8 & 3,3 & 22,7 \\
\hline Sistemas de Informação & 68,7 & 7,6 & 24 \\
\hline Matemática & 70,3 & 4,7 & \\
\hline
\end{tabular}

Fonte: Elaboração própria a partir dos dados coletados na pesquisa

Verifica-se certa variação em relação aos números individuais obtidos, o que se relaciona às especificidades de cada curso. Os cursos com maiores médias de evasão no período descrito foram Sistemas de Informação (68,7\%) e Matemática (70,3\%). Por outro lado, aqueles com maiores percentuais de permanência prolongada foram Engenharia de Energia (39,6\%) e Economia $(33,3 \%)$. Se analisados os maiores percentuais de conclusão, verifica-se que estão na ponta os cursos de Medicina (94,5\%) e Pedagogia (74,5\%).

Desses números citados, pode-se perceber, de início, que aqueles com maiores médias de evasão e retenção possuem em suas estruturas curriculares uma quantidade expressiva de disciplinas próprias das ciências exatas, o que pode ser um fator explicativo importante para o desempenho acadêmico e a ocorrência dos fenômenos da evasão e da retenção.

Ao mesmo tempo, é preciso esclarecer que um conjunto complexo de fatores atua como intervenientes na trajetória acadêmica. Entre esses destacam- 
se: a modalidade (licenciatura ou bacharelado), o período de oferta, a atratividade da carreira, o perfil socioeconômico dos estudantes, dentre outros ${ }^{10}$.

Os dados referentes à conclusão de curso mostram a complexidade inerente à trajetória acadêmica, visto que o curso de Pedagogia, por exemplo, que corresponde a uma área de pouco prestígio social, com atendimento a estudantes de baixo perfil socioeconômico (SOUZA; REAL, 2014), apresentou a segunda maior média de conclusão (74,5\%). A lógica, neste caso, seria a obtenção de altos índices de evasão, o que não foi observado, se comparadas as médias de evasão de Pedagogia e dos demais cursos analisados. Infere-se que para o curso de Pedagogia a explicação da evasão transcende os aspectos socioeconômicos, passando a englobar outros fatores explicativos como a empregabilidade ${ }^{11}$.

Desse modo, pode-se dizer que cada curso de graduação apresenta particularidades no comportamento dos fenômenos em discussão. Como se trata de um processo complexo, é preciso, ao menos, analisar algumas das interfaces que envolvem os fenômenos da trajetória escolar, buscando identificar possíveis tendências em variáveis diferenciadas. Tal procedimento pode contribuir para o aprimoramento das pesquisas que vêm sendo realizadas com a temática.

\section{PARTICULARIDADES DO ACESSO À EDUCAÇÃO SUPERIOR NA UFGD E ALGUNS FATORES EXPLICATIVOS PARA A EVASÃO, A PERMANÊNCIA PROLONGADA E A CONCLUSÃO DE CURSOS}

Com o intuito de verificar a interferência de alguns fatores na ocorrência dos processos de evasão, permanência prolongada e conclusão de curso, foi realizada análise dos dados gerais encontrados com a utilização de algumas categorias, as quais forneceram pistas importantes de como se comportam os fenômenos estudados na instituição de pesquisa. Abordaram-se os dados por colégio de conhecimento da Capes, por modalidade e por período de funcionamento do curso, por se considerar que se trata de variáveis relevantes para a análise.

Acredita-se que os dados analisados desse modo podem retratar uma realidade mais ampla, a qual se associa aos aspectos institucionais do conjunto

10 Considerando o limite deste texto, não se tratou dos dimensionamentos das influências de cada fator apontado. Para maior aprofundamento sobre a temática ver: Tinto (1975).

$11 \quad$ Nesse sentido ver: Alves; Pinto (2011). 
de Ifes, que têm implementado ações similares em seus cursos, embora essas similaridades possam não ser preponderantes para a ocorrência dos fenômenos em discussão.

Quando agrupados os cursos da UFGD em Colégios do Conhecimento, de acordo com classificação da Capes, constata-se certa polarização em relação ao Colégio de Ciências Exatas, Tecnológicas e Multidisciplinar, que detêm a maior média de evasão para o período considerado, e o Colégio de Ciências da Vida, para o qual a média foi menor.

\section{Gráfico 1 - Percentuais médios de evasão nos cursos de graduação por Colégio de Conhecimento. UFGD/2006-2009}

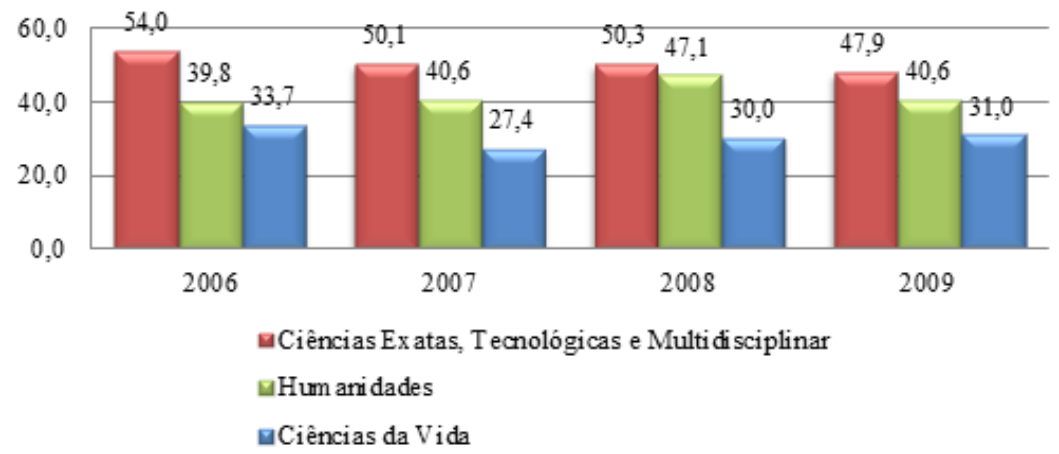

Fonte: Elaboração própria a partir dos dados coletados na pesquisa.

Se contrastados esses dados com os dados individuais dos cursos, observa-se que os cursos de Medicina e Agronomia, que apresentaram as menores taxas de evasão, impulsionam os percentuais menos acentuados do Colégio de Ciências da Vida. Por outro lado, os cursos de Matemática e Sistemas de Informação, que mostraram as maiores taxas de evasão, também contribuem de modo significativo para o resultado expresso no Colégio de Ciências Exatas, Tecnológicas e Multidisciplinar.

Quando verificados os percentuais de permanência prolongada por Colégio do conhecimento, obtém-se o resultado expresso no Gráfico 2. 


\section{Gráfico 02 - Percentuais médios de permanência prolongada nos cursos de graduação por Colégio do conhecimento. UFGD/2006-2009}

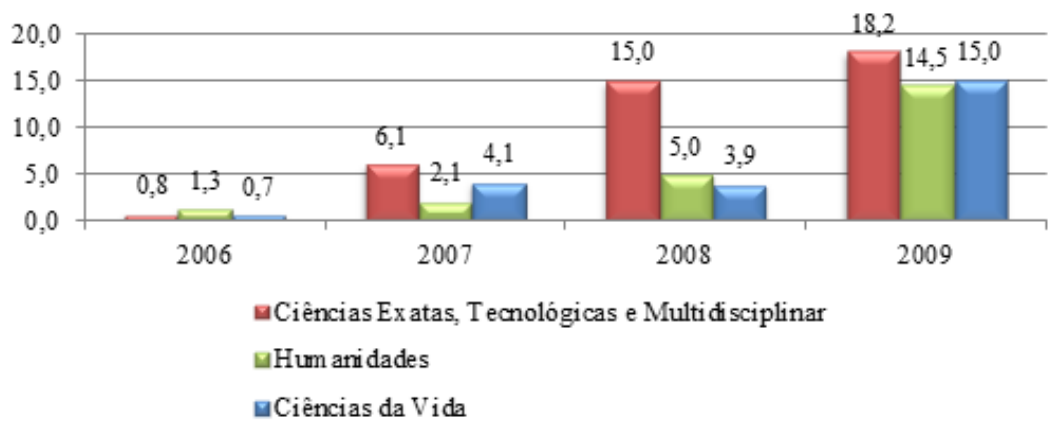

Fonte: Elaboração própria a partir dos dados coletados na pesquisa

Assim como para a evasão, verifica-se que o colégio de Ciências Exatas, Tecnológicas e Multidisciplinar também correspondeu àquele com maiores taxas de permanência prolongada no período estudado.

No contexto da década de 1990, a literatura já registrava as dificuldades em possibilitar a permanência dos alunos em cursos que possuem cargas horárias elevadas de disciplinas que fazem uso de matemática, apontando-se, assim, a relação existente entre esse aspecto e as taxas de evasão e retenção desses cursos (BRAGA; MIRANDA-PINTO; CARDEAL, 1997).

Por outro lado, não se pode perder de vista que a dificuldade no aprendizado de disciplinas exatas por estudantes nos dias atuais pode ser decorrente de um contexto histórico, em que, tradicionalmente, o ensino humanista se sobressaiu com maiores ênfases em relação ao de disciplinas ligadas à matemática, conforme indicam Chervel e Compère (1999). Para esses autores, na história da educação ocidental as humanidades erigiram-se em um alicerce sólido, tornando-se tradição, em detrimento ao ensino das ciências exatas, havendo, inclusive, resquícios em preconcebê-las como de difícil entendimento.

Desse modo, os resultados obtidos no presente artigo para esse grupo do conhecimento não se encontram dissociados de uma realidade mais ampla, dado que, tradicionalmente, os cursos de exatas vêm apresentando percentuais de evasão superiores a outros cursos do contexto brasileiro (SILVA FILHO et al., 2007).

Quando feita a análise dos percentuais de conclusão por Colégio de conhecimento, observa-se que o conjunto de cursos classificados como Ciências 
da Vida apresentam maiores percentuais durante todo o período analisado, seguido pelo Colégio de Humanidades e, por último, o de Ciências Exatas, Tecnológicas e Multidisciplinar.

\section{Gráfico 03 - Percentuais médios de conclusão nos cursos de graduação por Colégio do conhecimento. UFGD/2006-2009}

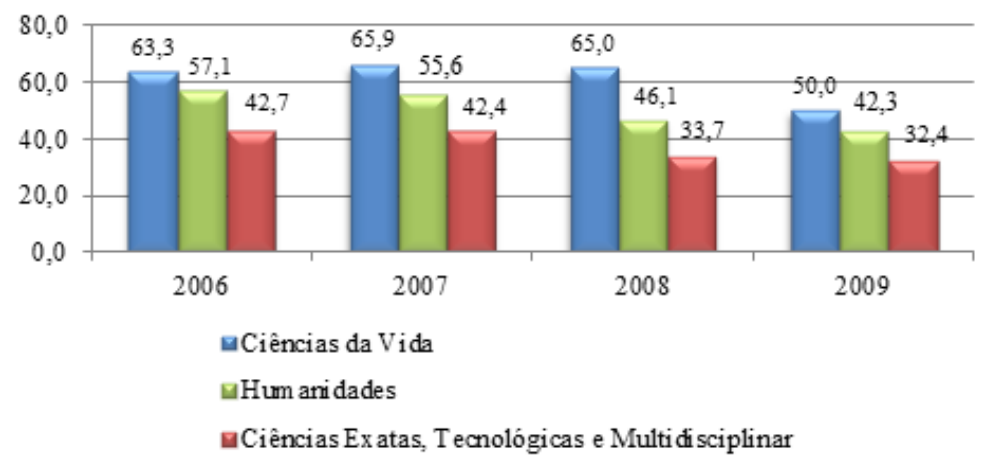

Fonte: Elaboração própria a partir dos dados coletados na pesquisa

Constata-se que o percentual de conclusão vem diminuindo em todos os anos para os colégios de Humanidades e de Ciências Exatas, Tecnológicas e Multidisciplinar. Para o de Ciências da Vida, houve diminuição significativa entre 2008 e 2009.

Os números visualizados em 2009 revelam-se menores em todos os grupos, o que pode ser justificado, em parte, pelo fato de ser o período mais recente analisado, em que parcela dos alunos ingressantes no ano ainda está com vínculo ativo com a instituição, estando em permanência prolongada.

Entretanto, em verificação mais precisa, constata-se que a diminuição significativa em 2009 no grupo de Ciências da Vida revela que alguns cursos dessa área passaram a apresentar maiores percentuais de retenção, dado que a evasão não aumentou neste período e, além disso, a conclusão no tempo mínimo de integralização do curso diminuiu no mesmo período. Nessa direção, tal constatação também é válida para os demais grupos. 


\section{Gráfico 4 - Percentuais médios de conclusão nos cursos de graduação no tempo mínimo de integralização por Colégio do Conhecimento. UFGD/2006-2009}

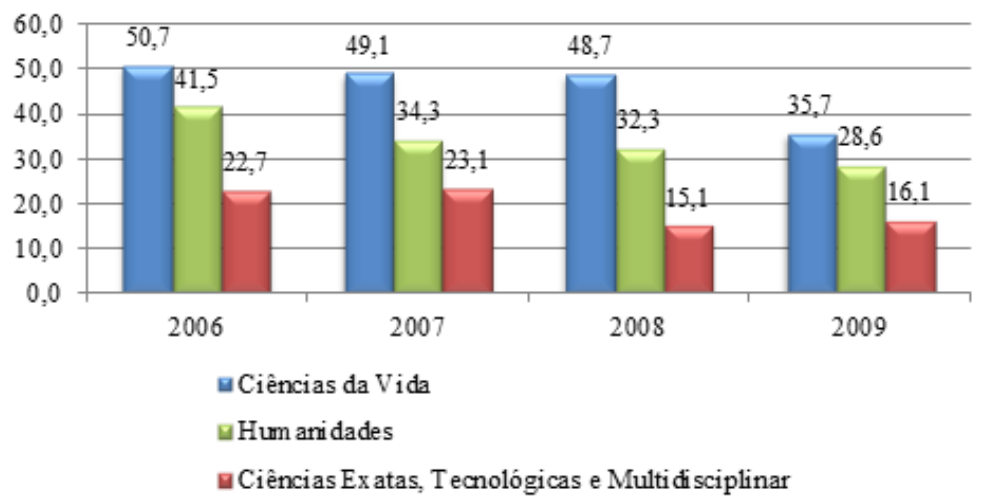

Fonte: Elaboração própria a partir dos dados coletados na pesquisa

Visualiza-se a mesma tendência, em relação ao Gráfico 3, com o Colégio de Ciências da Vida apresentando maiores percentuais de conclusão no tempo mínimo de integralização, seguidos pelas Humanidades e Ciências Exatas, Tecnológicas e Multidisciplinar.

Visto que o campo científico do curso de graduação apresentou relação com a permanência do estudante na instituição, é preciso considerar que o despreparo acadêmico do aluno que chega à universidade, sobretudo em disciplinas que fazem uso da matemática, pode estar responsabilizando em certa medida seu insucesso ${ }^{12}$.

Seria preciso repensar o papel da instituição no acolhimento do estudante e, mesmo, a necessidade da definição de políticas públicas voltadas para o atendimento estudantil, para que o aluno consiga acompanhar o curso em que escolheu ingressar. Algumas providências, como a oferta de disciplinas de nivelamento antes da oferta de disciplinas de cálculo e afins e o investimento em aperfeiçoamento da didática dos professores (OLIVEIRA et al., 2004), bem como a manutenção e o fortalecimento de programas de monitoria no âmbito da universidade, poderiam influenciar positivamente na trajetória escolar dos estudantes de graduação. 
No entanto, considera-se que não apenas a área vinculada interfere nessa trajetória, mas também outros fatores. A questão do reconhecimento da profissão é um deles. De modo geral, partiu-se da premissa de que aqueles cursos de mais baixo prestígio possuem taxas mais elevadas de evasão.

Como exemplificação e com o intuito de fundamentar essa argumentação, procurou-se analisar as taxas de evasão, de permanência prolongada e de conclusão entre os cursos de bacharelado e licenciatura.

\section{Gráfico 5 - Percentuais médios de evasão nos cursos de graduação por modalidade. UFGD/2006-2009}

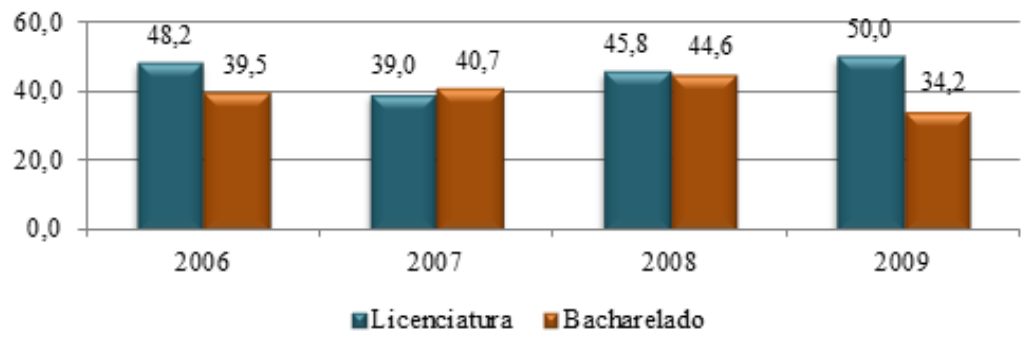

Fonte: Elaboração própria a partir dos dados coletados na pesquisa

\section{Gráfico 6 - Percentuais de conclusão nos cursos de graduação por modalidade. UFGD/2006-2009}

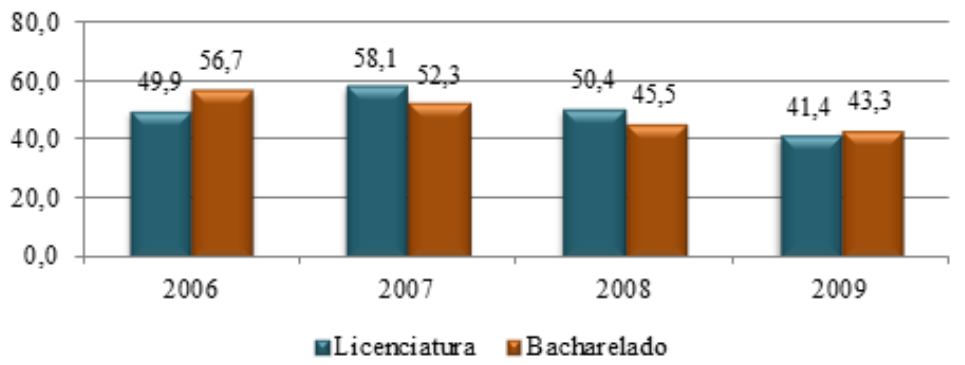

Fonte: Elaboração própria a partir dos dados coletados na pesquisa

Foram encontrados valores oscilantes para a evasão e para a conclusão do curso ao longo dos anos pesquisados, o que leva a crer que, após o ingresso do aluno no curso, a modalidade escolhida pode ser fator de peso pouco elevado 
para a decisão do estudante em conclui-lo, embora a relação licenciatura versus bacharelado se encontre articulada à questão do prestígio social das profissões (BUENO, 1993; ADACHI, 2009; MUZZI, 2015).

Porém, é preciso esclarecer que, no ano de 2009, a média de evasão na licenciatura $(50 \%)$ e no bacharelado $(34,2 \%)$ apresentou uma diferença mais expressiva em relação aos anos anteriores. Para a conclusão de curso, se feita a média geral de todo o intervalo de tempo pesquisado, obtém-se 49,45\% de conclusão para os bacharelados e de 49,95\% para as licenciaturas.

Nesse sentido, as oportunidades ampliadas de emprego para profissionais formados para a docência na Educação Básica pode estar contribuindo para a conclusão de curso na universidade investigada, alcançando determinado equilíbrio de percentuais quando se compara à formação nos bacharelados.

Por outro lado, é preciso levar em conta a relação existente entre os dados de evasão, de conclusão e de permanência prolongada.

\section{Gráfico 7 - Percentuais médios de permanência prolongada nos cursos de graduação por modalidade. UFGD/2006-2009}

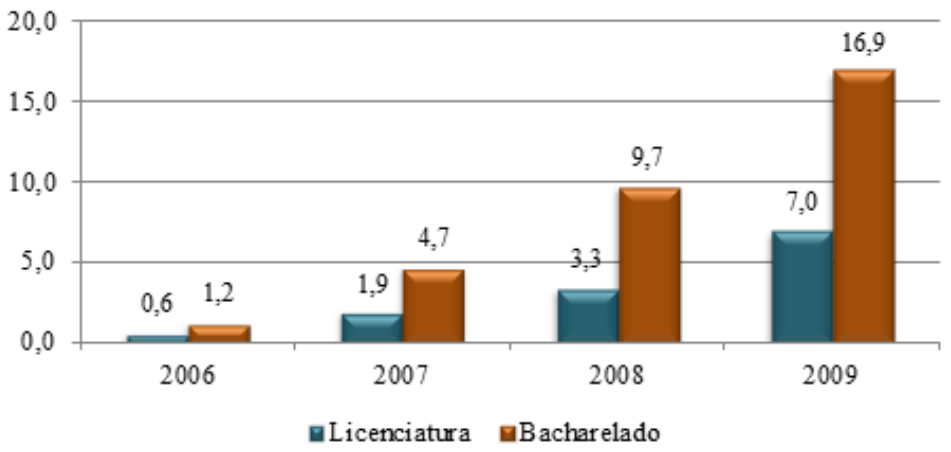

Fonte: Elaboração própria a partir dos dados coletados na pesquisa

Constata-se que, em média, o conjunto de cursos de Bacharelado apresenta maiores percentuais de permanência prolongada em todos os anos pesquisados, complementando os dados anteriormente expostos. Para os ingressantes em 2009, por exemplo, 43,3\% (Gráfico 6) concluíram o curso, porém, 16,9\% (Gráfico 7) ainda possuem chances de obter a formação. Por outro lado, para os ingressantes nas licenciaturas em 2009, 41,4\% (Gráfico 6) concluíram o curso e apenas 7\% (Gráfico 7) ainda possuem condições de concluir o curso. Para esse mesmo ano, a diferença de evasão entre licenciatura e bacharelado ultrapassou os 15\% (Gráfico 5), com o bacharelado evadindo menos. 
Desse modo, mesmo que os dados expressos nos gráficos 5 e 6 mostrem, à primeira vista, oscilações pouco expressivas, é preciso notar que os dados de permanência prolongada são relevantes para a análise e possibilitam um delineamento mais detalhado dos fenômenos da trajetória escolar.

Assim, pode-se dizer, de modo geral, que os ingressantes nos cursos de bacharelado evadem menos e permanecem mais tempo na instituição, quando comparados aos alunos de licenciatura. Infere-se a esse respeito que os cursos de bacharelado têm como característica a presença de estudantes com melhor perfil socioeconômico, e, portanto, com mais condições de permanecer e concluir o curso, mesmo em período superior ao tempo ideal previsto para a sua integralização.

Esse fator ainda pode ser associado ao fato de que um número razoável de cursos de bacharelado é ofertado em tempo integral. Constatou-se que, para este período o número de permanentes prolongados também foi mais elevado, inferindo-se que existe, ainda, uma relação entre o período de oferta do curso e os processos em discussão. Portanto, há nexos explicativos entre a permanência estudantil, a modalidade de bacharelado e a oferta em tempo integral.

Se retratada a permanência prolongada entre os cursos integrais e nãointegrais, obtém-se o resultado exposto no gráfico 08 .

\section{Gráfico 8 - Percentuais médios de permanência prolongada nos cursos de graduação por turno de funcionamento. UFGD/2006-2009}

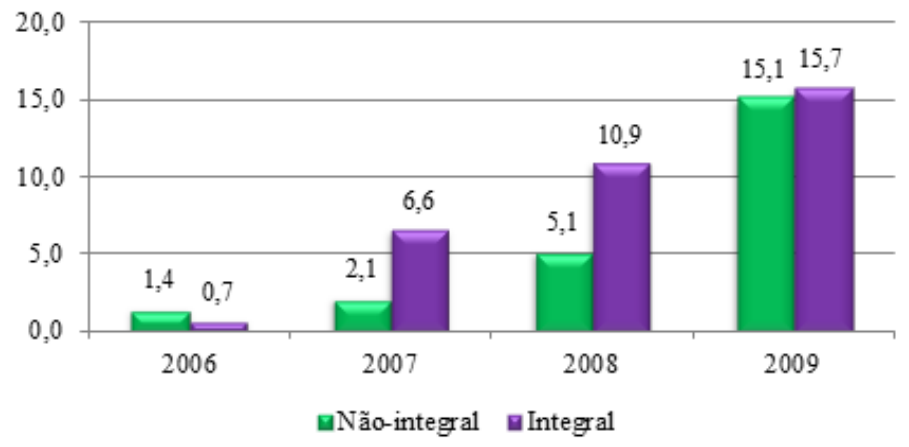

Fonte: Elaboração própria a partir dos dados coletados na pesquisa

Com diferenças maiores de percentuais entre os anos de 2007 e 2008, pode-se dizer que, de forma geral, os cursos ofertados em período integral correspondem àqueles de maiores percentuais de permanência prolongada.

Esse resultado, associado aos apresentados anteriormente para a permanência prolongada, permite expor um possível padrão para a ocorrência do 
processo de retenção na UFGD. Observa-se que cursos de período integral, do Colégio de Ciências Exatas, Tecnológicas e Multidisciplinar que conferem grau de bacharel são aqueles que retêm em maior medida os acadêmicos na instituição.

No que se refere à conclusão de curso por período de oferta, o gráfico 9 expõe os resultados encontrados:

\section{Gráfico 9-Percentuais médios de conclusão nos cursos de graduação por turno de funcionamento. UFGD/2006-2009}

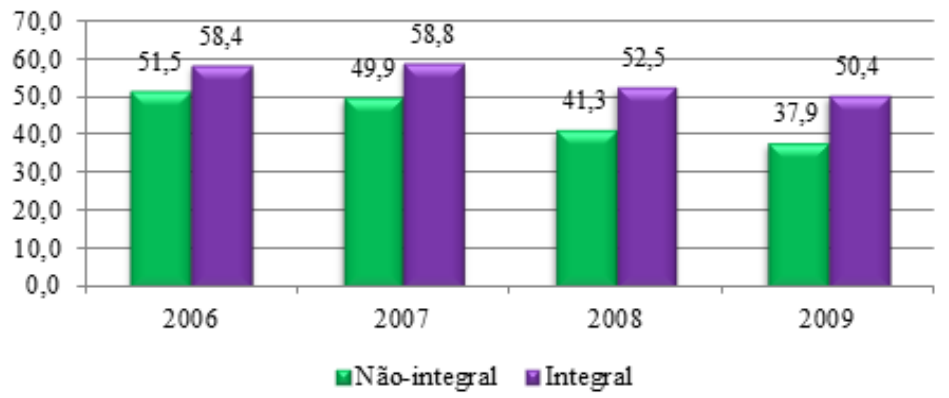

Fonte: Elaboração própria a partir dos dados coletados na pesquisa

Observa-se que, embora retenham em maior medida os estudantes, os cursos integrais apresentam maior taxa de conclusão.

Esse resultado pode estar associado a fatores sociais, dado que os cursos ofertados em período integral correspondem, de forma geral, àqueles que representam carreiras profissionais mais atrativas e de melhor remuneração ${ }^{13}$, o que pode estar influenciando a decisão do estudante de concluir ou abandonar o curso, mesmo que fique retido por mais tempo na instituição.

Desse modo, a evasão entre os cursos integrais e não-integrais também está articulada e, ao mesmo tempo, contraposta a este resultado, conforme se visualiza no gráfico 10.

13 Cumpre expor que esses cursos correspondem àqueles com maior concorrência no vestibular, o que pode estar resultando no ingresso de estudantes de perfil socioeconômico diferenciado. 


\section{Gráfico 10 - Percentuais médios de evasão nos cursos de graduação por turno de funcionamento. UFGD/2006-2009}

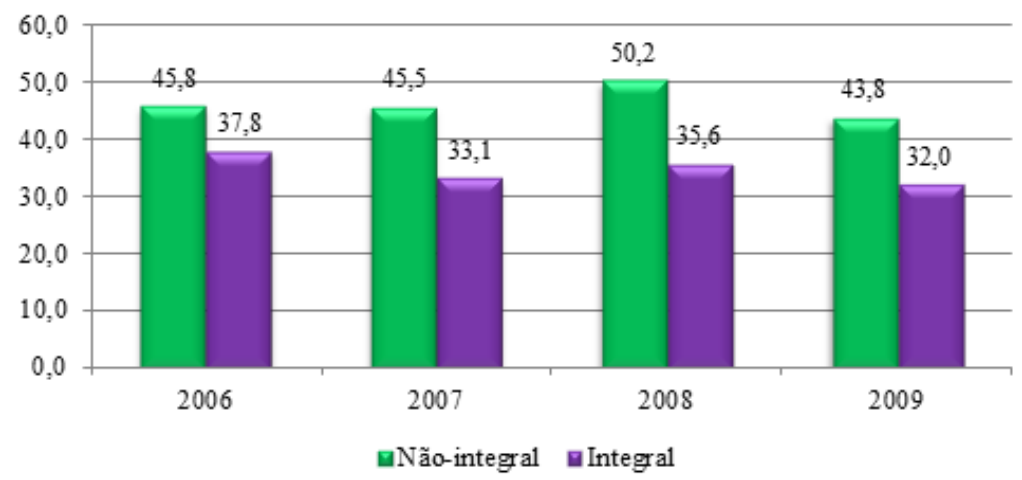

Fonte: Elaboração própria a partir dos dados coletados na pesquisa

Verifica-se que os cursos não-integrais apresentaram maiores médias de evasão em todos os anos de estudo ${ }^{14}$. De modo geral, pode-se dizer que os cursos ofertados apenas em um período, especialmente no noturno, normalmente são aqueles voltados para o estudante trabalhador, cujo perfil socioeconômico pode estar representando importante fator para a análise dos fenômenos da trajetória acadêmica e precisariam ser investigados em possíveis desdobramentos desta pesquisa.

De modo geral, com embasamento na literatura (OLIVEIRA, et al., 2004; TINTO, 1975), é possível argumentar que diante das primeiras dificuldades encontradas no início do curso, ou mesmo da falta de integração ao curso e/ou à instituição, a evasão corresponde a uma decisão relevante para os estudantes.

Em outra análise, constatou-se que mais da metade dos alunos que evadem dos cursos na UFGD, o fazem nos dois primeiros períodos, fato que traz para reflexão o papel da universidade no acolhimento a esses acadêmicos, o que também remete, inclusive, ao período anterior ao ingresso. Entretanto, mesmo com uma concentração maior de evasão logo no início, verificou-se que há alunos evadindo, também, nos períodos finais do curso.

Em análise individual do curso de Matemática, o qual apresentou a maior média geral de evasão no período estudado (Tabela 3), verificou-se que

14 Cumpre ressaltar que, com exceção de Matemática e Ciências Sociais, os cursos não-integrais da instituição eram ofertados no período noturno entre 2006 e 2009. 
aproximadamente $20 \%$ dos estudantes que ingressaram na instituição entre 2006 e 2009 evadiu após o quarto ano de curso. Esse dado corrobora a tese de que a retenção também corresponde a um dos fatores que engendra a evasão.

Nessa direção, outro achado relevante no decorrer da pesquisa referiuse à verificação de que, dentre os alunos evadidos na UFGD entre 2006 e 2009, $21 \%$ foram matriculados em outros cursos na mesma instituição, antes ou após o período aqui analisado, o que mostra que a inadaptação em um primeiro curso de ingresso os leva a realizar novas tentativas.

Entretanto, o ponto que mais chama a atenção em relação a esses sujeitos é que o percentual de evasão configurou-se também como uma taxa elevada. Do total de alunos matriculados em outro curso após a primeira evasão analisada, $23 \%$ foram diplomados no novo curso, $30 \%$ ainda se encontravam matriculados no primeiro semestre de 2015 e $43 \%$ evadiram mais uma vez ${ }^{15}$.

Esses fatos permitem a observar que há fatores intervenientes no processo de evasão que implicam questões internas e externas às instituições, bem como fatores intrínsecos ao próprio estudante. Nesse sentido, Tinto (1975) explica que caberia às IES procurar meios de integrar o estudante ao contexto universitário, o que minimizaria efeitos negativos da trajetória acadêmica.

Diante do atual contexto de expansão, em que as possibilidades de se cursar uma graduação têm sido ampliadas de modo acentuado, a mobilidade de estudantes entre cursos e instituições pode referir-se a um fenômeno tendencial. Trata-se do aluno buscando as melhores opções que lhe permitam identificar suas potencialidades.

Entretanto,considera-sequeesseprocessonãoelimina as responsabilidades institucionais, que deveriam ser ampliadas diante desse cenário, uma vez que a implementação de ações, sobretudo nos primeiros períodos de curso, poderiam minimizar as elevadas taxas de evasão e contribuir para a efetivação do acesso à Educação Superior enquanto um processo de ingresso-permanência-formação qualificada $^{16}$.

\section{CONSIDERAÇÕES FINAIS}

Com análises amplas, o artigo permitiu fazer algumas inferências em relação a questões importantes que tratam da trajetória acadêmica de estudantes de graduação na UFGD.

$15 \%$ corresponde a situações não investigadas nesta pesquisa.
$16 \quad$ Nesse sentido, ver Silva e Veloso (2013). 
Mesmo com um processo de expansão estendendo-se em todo o País, no âmbito institucional, os números aqui registrados desvelam que esse movimento se apresentou com certa complexidade. Os imbróglios que envolvem a permanência estudantil têm-se configurado como um percalço para a garantia de um acesso à Educação Superior entendido como ingresso, permanência e conclusão de curso (SILVA; VELOSO, 2013).

Observa-se que a política nacional tem buscado minorar esses fatores por meio da realização de programas de assistência estudantil, sendo essa a ação mais presente e historicamente apontada como medida de controle da evasão. No entanto, observa-se que apesar da implementação em andamento de programas voltados para a permanência estudantil, as taxas de evasão se mantêm elevadas, decorrentes, inclusive, de fatores apontados ao longo do trabalho, dentre os quais aspectos internos à IES, como: (não) didática docente, falta de políticas de integração discente, questões curriculares, falta de infraestrutura adequada ao funcionamento do curso, carência de pessoal técnico e docente, dentre outros, e, ainda, outros aspectos externos à IES, como: baixa atratividade da carreira, remuneração baixa, empregabilidade, despreparo dos estudantes, baixo capital cultural decorrente dos fatores econômicos, entre outros. É preciso considerar, ainda aspectos intrínsecos aos estudantes.

Embora o conjunto de cursos da UFGD tenha apresentado taxas de evasão de pequenas oscilações, fixando-se em torno de 40\%, observou-se que a retenção corresponde a um fenômeno em ascensão na universidade pesquisada. Assim, a combinação de ambos os processos se trata de um agravante na trajetória acadêmica.

No que se refere às taxas de conclusão, embora o número de estudantes que concluíram o curso de ingresso se tenha mantido expressivo em alguns cursos, os dados gerais registrados estiveram em decréscimo com o passar dos anos.

De modo geral, os cursos pertencentes ao Colégio de Ciências da Vida e os ofertados em período integral corresponderam aos de maiores percentuais de conclusão. Esses dados se articulam aos de permanência prolongada, na medida em que a diminuição das taxas de conclusão foi acompanhada de aumento do número de estudantes retidos na instituição para além do tempo considerado ideal para o término.

Se consideradas as metas estabelecidas pelas políticas nacionais, expressas no Reuni e no PNE, que estabelecem a elevação gradual das taxas de aprovação até atingir os $90 \%$, pode-se dizer que os resultados obtidos na presente pesquisa apontam que o movimento de expansão da Educação Superior brasileira é bastante complexo. A média em torno de 50\% de conclusão, decrescente com o passar dos anos, corroboram essa afirmação. 
A análise se aprofunda quando se verifica que a UFGD participou dos principais programas de acesso e permanência criados pelo governo federal nas últimas décadas e os resultados acadêmicos alcançados por essa instituição contradizem as definições da própria política em implementação.

Os meandros do acesso à Educação Superior explicitam que há necessidade da combinação de políticas universais e focalizadoras, de forma a atender ao conjunto dos fatores intervenientes no fenômeno da evasão, tanto sociais quanto institucionais e individuais.

Assim, o conhecimento da realidade local e das especificidades dos cursos de graduação ofertados precisa corresponder a fatores norteadores para o processo de implementação de políticas pensadas para o âmbito nacional.

Essas premissas poderiam contribuir para potencializar o êxito na trajetória acadêmica, visto que a evasão e a permanência prolongada têm caracterizado um processo contraditório em relação aos objetivos previstos nacionalmente para a Educação Superior, em que se espera que o aluno ingresse, permaneça no sistema satisfatoriamente e, por fim, conclua o curso.

\section{REFERÊNCIAS}

ADACHI, Ana Amélia Chaves Teixeira. Evasão e evadidos nos cursos de graduação da Universidade Federal de Minas Gerais. 2009. 214 f. Dissertação (Mestrado em Educação) - Universidade Federal de Minas Gerais, Belo Horizonte, 2009.

ALMEIDA, Cínthia Soares. Dificuldades de aprendizagem em Matemática e a percepção dos professores em relação a fatores associados ao insucesso nesta área. 2006. Disponível em: <http://www.ucb.br/sites/100/103/ tcc/12006/cinthiasoaresdealmeida.pdf>. Acesso em $1^{\circ}$ jun 2015.

ALVES, Thiago; PINTO, José Marcelino de Rezende. Remuneração e características do trabalho docente no Brasil: um aporte. Cadernos de Pesquisa, São Paulo, v. 41, n. 143, p. 606 - 639, maio-ago. 2011.

AZEVEDO, Janete Maria Lins. A educação como política pública. Campinas, SP: Autores Associados, 1997.75 p. 
BRAGA, Mauro Mendes; MIRANDA-PINTO, Clotilde Otília Barbosa; CARDEAL, Zenilda de Lourdes. Perfil sócio-econômico dos alunos, repetência e evasão no curso de Química da UFMG. Química Nova, Belo Horizonte, 20(4), p. 438-444, 1997.

BRASIL. Sinopses Estatísticas da Educação Superior - Graduação: Instituto de Estudos e Pesquisas Educacionais Anísio Teixeira, 2015. Disponível em: < http://portal.inep.gov.br/superior-censosuperior-sinopse>. Acesso em: 06 jun. 2015.

. Lei $\mathrm{n}^{\circ}$ 12.711, de 29 de agosto de 2012. Dispõe sobre o ingresso nas universidades federais e nas instituições federais de ensino técnico de nível médio e dá outras providências. Diário Oficial [da] República Federativa do Brasil, Brasília, DF, 30 ago. 2012. Disponível em: < http://pesquisa.in.gov.br/imprensa/ jsp/visualiza $/$ index.jsp?jornal $=1 \&$ pagina $=1 \&$ data $=30 / 08 / 2012>$. Acesso em 06 jun. 2015.

Portaria Normativa $n^{\circ} 25$, de 28 de dezembro de 2010. Dispõe sobre o Programa Nacional de Assistência Estudantil para as instituições de Educação Superior públicas estaduais - PNAEST. Diário Oficial [da] República Federativa do Brasil, Brasília, DF, 29 dez. 2010b. Disponível em: <http:// pesquisa.in.gov.br/imprensa/jsp/visualiza/index.jsp?jornal $=1 \&$ pagina $=36 \& \mathrm{da}$ ta $=29 / 12 / 2010>$. Acesso em: 10 jun. 2015.

Decreto $n^{\circ}$ 7.234, de 19 de julho de 2010. Dispõe sobre o Programa Nacional de Assistência Estudantil - PNAES. Diário Oficial [da] República Federativa do Brasil, Brasília, DF, 20 jul. 2010a. Disponível em: <http:// pesquisa.in.gov.br/imprensa/jsp/visualiza/index.jsp?jornal $=1 \&$ pagina $=5 \& \mathrm{da}$ ta $=20 / 07 / 2010>$. Acesso em: 10 jun. 2015.

. Lei n ${ }^{\circ}$ 11.892, de 29 de dezembro de 2008. Institui a Rede Federal de Educação Profissional, Científica e Tecnológica, cria os Institutos Federais de Educação, Ciência e Tecnologia, e dá outras providências. Diário Oficial [da] República Federativa do Brasil, Brasilia, DF, 30 dez. 2008. Disponível em: $<$ http://pesquisa.in.gov.br/imprensa/jsp/visualiza/index.jsp?jornal=1\&pagina $=1 \&$ data $=30 / 12 / 2008>$. Acesso em: 31 jul. 2015 .

Decreto $n^{\circ}$ 6.096, de 24 de abril de 2007. Institui o Programa de Apoio a Planos de Reestruturação e Expansão das Universidades Federais - REUNI. 
Diário Oficial [da] República Federativa do Brasil, Brasília, DF, 25 abr. 2007. Disponível em: < http://pesquisa.in.gov.br/imprensa/jsp/visualiza/index.jsp?jor nal $=1 \&$ pagina $=7 \&$ data $=25 / 04 / 2007>$. Acesso em: 10 jun. 2015.

Decreto $\mathrm{n}^{\mathrm{0}}$ 5.800, de 08 de junho de 2006. Dispõe sobre o Sistema Universidade Aberta do Brasil - UAB. Diário Oficial [da] República Federativa do Brasil, Brasília, DF, 09 jun. 2006. Disponível em: <http://pesquisa.in.gov. $\mathrm{br} /$ imprensa/jsp/visualiza/index.jsp?jornal=1\&pagina $=4 \& d a t a=09 / 06 / 2006>$. Acesso em 06 jun. 2015.

Lei n ${ }^{\circ} 11.096$, de 13 de janeiro de 2005. Institui o Programa Universidade para Todos - PROUNI, regula a atuação de entidades beneficentes de assistência social no ensino superior; altera a Lei no 10.891, de 9 de julho de 2004, e dá outras providências. Diário Oficial [da] República Federativa do Brasil, Brasília, DF, 14 jan. 2005. Disponível em: < http:/ / pesquisa.in.gov.br/imprensa/jsp/visualiza/ index.jsp?jornal $=1 \&$ pagina $=7 \&$ data $=14 / 01 / 2005>$. Acesso em: 06 jun. 2015.

Ministério da Educação. Expandir até ficar do tamanho do Brasil. Brasília, DF, 2004. Disponível em: <www.mec.gov.br>. Acesso em: 05 jun. 2017.

Medida Provisória no 1.827, de 27 de maio de 1999. Dispõe sobre o Fundo de Financiamento do Estudante do Ensino Superior e dá outras providências. Diário Oficial [da] República Federativa do Brasil, Brasília, DF, 28 maio 1999. Disponível em :<http://pesquisa.in.gov.br/imprensa/jsp/visualiza/index. jsp?jornal=1\&pagina=98\&data=28/05/1999> . Acesso em: 06 jun. 2015.

Diplomação, retenção e evasão nos cursos de graduação em instituições de ensino superior públicas. Brasília: ANDIFES/ABRUEM/ SESu/MEC, 1997. 152 p.

BUENO, José Lino Oliveira. A evasão de alunos. Paidéia, Ribeirão Preto, n. 5, p. 9-16, ago. 1993.

CARVALHO, Cristina Helena Almeida. A política pública de expansão para a Educação Superior entre 1995 e 2010: uma abordagem neoinstitucionalista histórica. Revista Brasileira de Educação, Rio de Janeiro, v. 20, n. 60, p. 51-76, jan./mar. 2015. 
CHERVEL, André; COMPÈRE, Marie-Madeleine. As humanidades no ensino. Educação e Pesquisa, São Paulo, v. 25, n. 2, p. 149-170, jul./dez. 1999.

GOMES, Alfredo Macedo; MORAES, Karine Nunes de. Educação Superior no Brasil contemporâneo: transição para um sistema de massa. Educação \& Sociedade, Campinas, SP, v. 33, n. 118, p. 171-190, jan./mar. 2012.

LOBO, Maria Beatriz de Carvalho Melo. Panorama da evasão no ensino superior brasileiro: aspectos gerais das causas e soluções. In: HORTA, C. E. R. (Org. e Coord.). Evasão no ensino superior brasileiro. Brasília: ABMES Cadernos, 2012. p. 9-58.

MUZZI, Luiza. Baixa procura e evasão acendem alerta em licenciaturas na UFMG. 2015. Disponível em: < http://www.otempo.com.br/cidades/ baixa-procura-e-evas \% C3\% A3o-acendem-alerta-em-licenciaturas-naufmg-1.1040448>. Acesso em: 08 jun. 2015.

NUNES, Raul Ceretta. Panorama Geral da Evasão e Retenção no Ensino Superior no Brasil (IFES). In: Encontro Nacional de Pró-Reitores de Graduação, 27, 2013, Recife. Painel... Recife: FORGRAD, 2013. Disponível em: <http:// www.forgrad.com.br/apresentacoes/dia1/2013\%20-\%20Painel $\% 20$ Forgrad $\% 20$ Agosto\%20-\%20Evasao.pdf>. Acesso em 29 jun. 2014.

OLIVEIRA, Romualdo Portela. et al. Acompanhamento da trajetória escolar dos alunos da Universidade de São Paulo ingressantes de 1995 a 1998. São Paulo: CEPPPE-FEUSP, 2004, 142p.

SILVA, Glauco Peres. Análise de evasão o ensino superior: uma proposta de diagnóstico de seus determinantes. Avaliação, Campinas; Sorocaba, v. 18, n. 2, p. 311-333, jul. 2013.

SILVA, Maria das Graças Martins; VELOSO, Tereza Christina Mertens Aguiar. Acesso nas políticas de Educação Superior: dimensões e indicadores em questão. Avaliação, Campinas; Sorocaba, v. 18, n. 3, p. 727-747, nov. 2013.

SILVA FILHO, Roberto Leal Lobo et al. A evasão no Ensino Superior brasileiro. Cadernos de Pesquisa, São Paulo, v. 37, n. 132, p. 641-659, set./dez. 2007. 
SOUZA, Mary Ane; REAL, Giselle Cristina Martins. O ingressante ao curso de Pedagogia da UFGD: análise exploratória de convergências para a educação básica. Quaestio, Sorocaba, v. 16, p. 199-223, maio 2014.

TINTO, Vincent. Dropout from higher education: a theoretical synthesis of recent research. Review of Educational Research, Washington, v. 45, n. 1, p. 89-125, Winter, 1975.

JOSÉ DA SILVA SANTOS JUNIOR possui Mestrado em Educação pela Universidade Federal da Grande Dourados, Especialização em Metodologia do Ensino Superior (2011) e Educação a Distância (2012), pelo Centro Universitário da Grande Dourados, graduação em Ciências Biológicas (Licenciatura) pela Universidade Estadual de Mato Grosso do Sul (2007). Atualmente é Técnico em Assuntos Educacionais da Universidade Federal da Grande Dourados e Professor Formador e Conteudista na Faculdade de Educação a Distância da mesma instituição. E-mail: josejunior_ss@yahoo.com.br

GISELLE CRISTINA MARTINS REAL possui graduação em Pedagogia pela Universidade Federal de Mato Grosso do Sul (1988), graduação em Direito pelo Centro Universitário da Grande Dourados (1989), mestrado em Educação pela Universidade Federal de Mato Grosso do Sul (2000) e doutorado em Educação pela Universidade de São Paulo - USP (2007). Realizou, em 2011, estágio de pós-doutoramento na USP. Atualmente é professora associada da Universidade Federal da Grande Dourados, atuando na graduação e na pós-graduação stricto sensu. Tem experiência na área de Educação, com ênfase em Política Educacional, atuando principalmente com os temas avaliação e educação superior. E-mail: gcreal@terra.com.br 